
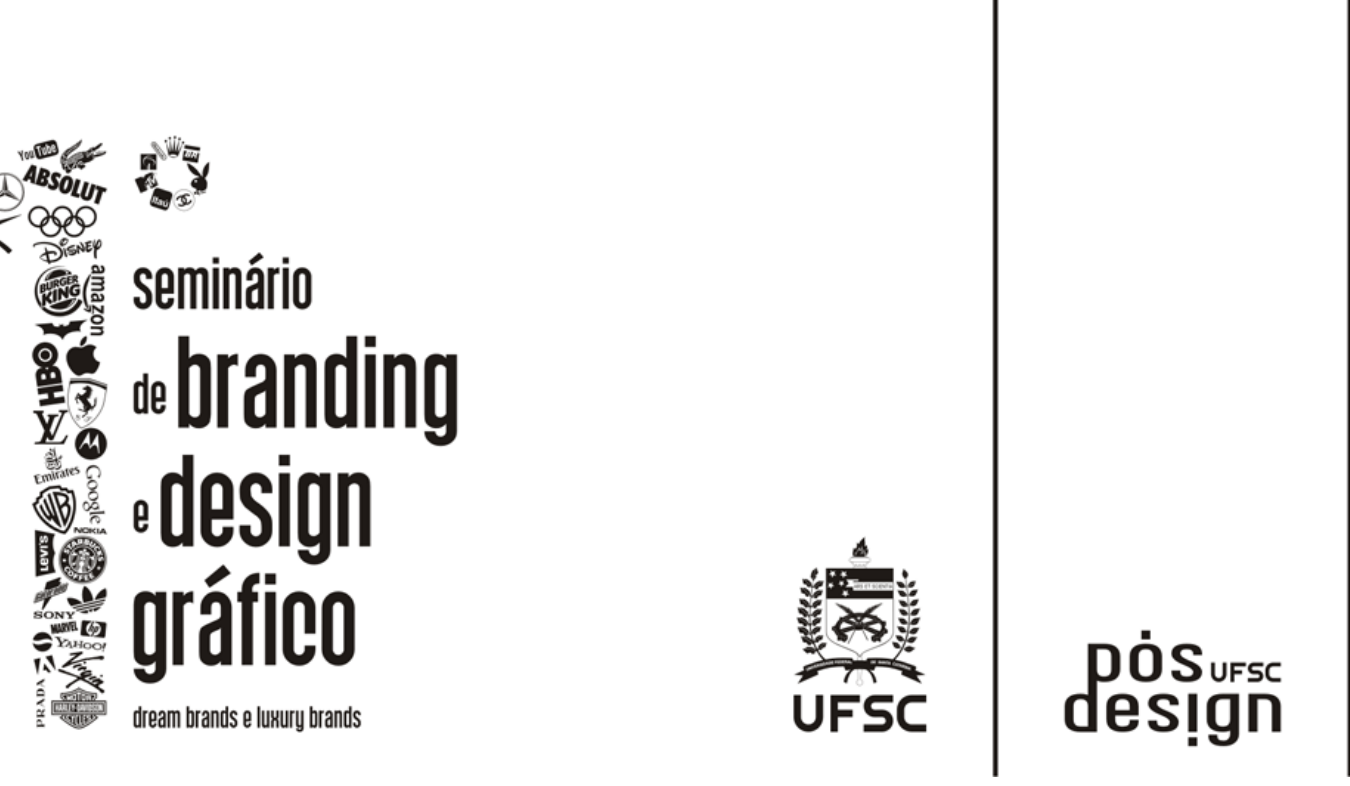

LOGO

\title{
Marca dos sonhos: metodologia de design e contribuição do branding para o desenvolvimento de marcas emocionais
}

Dream Brand: Design Methodology and the branding process contribution for the emotional brand development

Mônica Renneberg da Silva; Programa de Pós-Graduação em Design e Expressão Gráfica mo.renneberg@gmail.com

Dafne Fonseca Arbex; Programa de Pós-Graduação em Design e Expressão Gráfica dafnefa@gmail.com

\begin{abstract}
Resumo
O presente artigo defende que uma marca dos sonhos requer um forte apelo emocional e apresenta uma metodologia criada para o desenvolvimento de marcas emocionais, que foi aplicada ao projeto de design para a empresa "Chopp do Gus". O estudo metodológico é situado no contexto das metodologias já existentes, descrevendo os procedimentos técnicos e parte da projetação de Identidade Visual. Um aspecto necessário neste contexto é evidenciar o estudo da importância do branding como fator decisivo para que uma marca atue emocionalmente e obtenha sucesso de mercado, como marca dos sonhos, capaz de seduzir e atender simbolicamente os desejos do consumidor.
\end{abstract}

Palavras-chave: design, branding, metodologia.

\begin{abstract}
The present article defends that a dream brand requests a strong emotional appeal and presents a methodology created for the development of emotional brand, which was applied to the design project for the company "Chopp of Gus". The methodological study is placed in the context of the methodologies already known, describing the technical procedures and part of the Visual Identity design process. A necessary aspect in this context is to evidence the study of the branding importance as decisive factor for a brand mark to act emotionally and obtain market success, as dream brand, capable to seduce and to attend the symbolical consumer's desires.
\end{abstract}

Key-words: design, branding, methodology. 


\section{INTRODUÇÃO}

Vive-se em um mundo onde a economia já não é mais exclusivamente voltada para a indústria e produção de bens de consumo, e sim para as pessoas. O conceito de marcas de sucesso está relacionado aos estímulos e experiências sensoriais que determinados produtos têm com seus consumidores, que elegem o aspecto emocional como diferencial num mercado extremamente competitivo. Gobé (2002) define como marca emocional aquela que tem a capacidade de se comunicar com os consumidores no nível dos sentidos e das emoções, avivando as pessoas e forjando conexões profundas e duradouras.

Para Niemeyer (2002) uma marca só funciona se o produto for de encontro às necessidades e desejos do consumidor, satisfazendo-o em sua plenitude. Além de comunicar claramente o valor e os benefícios de seus produtos perante seus concorrentes e assegurar sua compreensão por parte do consumidor, a marca deve também inspirar confiança e contribuir para a consolidação de uma relação de lealdade por parte do consumidor.

Neste aspecto o branding atua como um conjunto de ações ligadas à gestão das marcas, compondo vantagens competitivas através do planejamento estratégico bem sucedido e do controle de esforços e ações. Isso visa garantir retornos de investimento promissores e bases sólidas para os clientes fiéis e cativos. Marcas, por serem intangíveis, quando bem gerenciadas podem ter vida útil infinita, e suas características intangíveis não podem ser copiadas. As marcas criam barreiras emocionais e filosóficas contra a concorrência, bem como vantagem competitiva sustentável de longo prazo (NUNES, 2003).

Através dos atributos emocionais, as pessoas deixam de comprar um produto para comprar um comportamento ou uma emoção. Gobé (2002) diz que é fundamental estimular os cinco sentidos dos consumidores, a partir do uso das cores e formas da marca de uma empresa ou produto, permitindo que eles façam associações mentais positivas com o produto.

Para fazer com que marcas regionais consigam atingir um nível emocional, observa-se a necessidade de desenvolvimento de uma metodologia específica de trabalho, com o intuito de adequar as questões da abrangência do branding e da "emoção das marcas" (GOBÉ, 2002) à situação de uma pequena empresa localizada em Florianópolis, no ramo de bares e casas noturnas.

\section{DESENVOLVIMENTO DA METODOLOGIA}

Para o desenvolvimento da metodologia a ser utilizada, foram discutidas metodologias de autores, como Bruno Munari, Mike Baxter, Flávio Santos e Gustavo Bomfim.

A sequiência escolhida foi a proposta por Munari - a de estudar o problema coletando e analisando dados, passando para a fase criativa, pela pesquisa e pela fase conclusiva na solução. (MUNARI, 1998). Além disso, foi utilizada como base a Metodologia do Desdobramento em 3 Etapas, de Flávio Santos (2000), que propõe três fases: Pré-concepção, Concepção e PósConcepção. Segundo Santos (2000), essa divisão de fases facilita a identificação das atividades a serem desenvolvidas, e as relações entre elas. Presumindo a necessidade de retornos em certos pontos, dividiu-se a metodologia em três grandes blocos, utilizando-se parte da proposta de Santos, - linear, porém com a possibilidade de retrocessos -, e parte do Método Cíclico com Retornos Predeterminados de Gustavo Bonfim (1995).

Foram sugeridas, também, novas ferramentas e técnicas para a concepção desta nova metodologia, sendo as mais importantes: Questionário, ou briefing ${ }^{1}$, para aplicação com o cliente

\footnotetext{
${ }^{1}$ Briefing é a etapa em que são coletadas todas as informações possíveis sobre o cliente, seu público-alvo, preferências e necessidades da empresa, entre outros. É um passo crucial, e irá nortear o trabalho.
} 
na etapa de pré-concepção; Tabelas ${ }^{2}$, para análise de dados; Brainstorming ${ }^{3}$, como auxílio do processo criativo dos estudantes de design; Painel Semântico ${ }^{4}$ para o momento de geração de alternativas e tabelas comparativas.

Durante o projeto a metodologia foi alterada em dois momentos: no primeiro quando a equipe julgou necessária a presença do cliente para aprovação dos conceitos definidos e do Painel Semântico, como forma de garantir que a equipe não precisaria rever os passos anteriores caso a proposta final não fosse aceita. Num segundo momento, outra modificação definida, com o objetivo de aproximar o cliente do grupo e facilitar a compreensão do trabalho que estava sendo realizado, e num contexto mais global, com a intenção de deixar o cliente ciente da seriedade do trabalho que estava sendo feito.

\section{ESTUDO DE CASO}

\subsection{Etapa de Pré-concepção}

Com a metodologia do projeto já estabelecida, iniciou-se a etapa de pré-concepção, na qual foi realizado o briefing junto ao cliente, e as pesquisas temáticas e de concorrência. Como diferenciais da empresa, o proprietário destacou o bom atendimento, o clima de informalidade entre os frequientadores do ambiente e os proprietários, a boa qualidade do Chopp e os pratos diferenciados em relação aos demais restaurantes da região. O público-alvo é bastante variado, abrangendo a faixa etária dos 25 aos 40 anos.

Percebeu-se então, a necessidade de uma identidade visual para a empresa, considerando tanto a choperia quanto o espaço para shows, além de aplicações solicitadas, como: placa, comanda, cardápio, cartão fidelidade, folder, sinalização, uniforme, brindes, bolachas de chopp, sinalização interna e externa, entre outros.

Os conceitos da empresa definidos pelo proprietário incluem o ambiente rústico e caseiro sendo, ao mesmo tempo, descontraído e familiar. As restrições do proprietário para a criação da marca são o uso de cores quentes e a (de) utilização de logotipia marcante.

Com os dados apresentados a equipe de designers iniciou a segunda etapa da metodologia, com a realização da pesquisa de campo, que inclui as pesquisas temáticas e de concorrência. Através do aprofundamento temático, pode-se obter maior know-how sobre o ramo e, através da pesquisa de concorrência, foi possível optar pela diferenciação: 1- atrair a atenção dos clientes com novidades ou 2- optar pela inclusão nas características já existentes, tentando descobrir os aspectos para serem destacados.

\subsection{Etapa de Concepção}

O desenvolvimento do painel semântico caracterizou os conceitos de maior relevância em relação às emoções que a empresa pode despertar, tais como: descontração, bom gosto, agitação e satisfação. Além dos conceitos foi possível retirar do painel semântico alguns aspectos formais,

\footnotetext{
${ }^{2}$ Tabelas de análise são instrumentos para a visualização das informações sobre concorrência, mercado, processos de fabricação, entre outras.

${ }^{3}$ Brainstorming é um recurso de produção e expressão de idéias, utilizado no momento criativo que antecede a definição dos conceitos da marca.

${ }^{4}$ Painel semântico é o produto de uma pesquisa, com seleção e composição de imagens, que auxilia na definição das características semânticas e conceituais que o produto gráfico deverá ter, mapeando o público-alvo e produtos com conceitos semelhantes (Baxter, 1998).
} 
que auxiliariam na construção da marca, como a recorrência de agrupamentos circulares, a grande ocorrência do vermelho e a presença dos copos de chopp, principalmente a tulipa. (fig. 1).

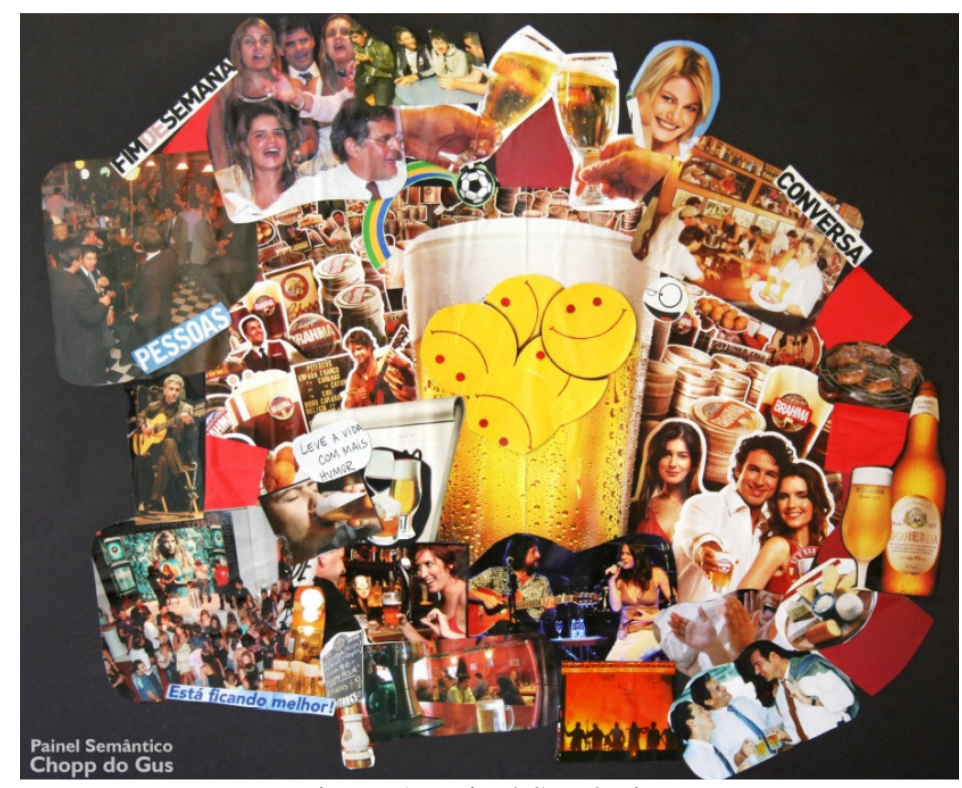

Figura 1: Painel Semântico

Após diversas alternativas, optou-se pela marca composta por símbolo e logotipo, apresentada a seguir (fig. 2).

O vermelho utilizado, com intensidade rebaixada, aproximando-se dos tons de terra ou ferrugem, remete à cor do próprio ambiente da choperia, que apresenta características rústicas, dando à marca gráfica um aspecto coerente com o ambiente que representa. Estilo, personalidade e paixão são atributos marcantes associadas ao vermelho, que é uma cor fortemente ligada às emoções, porque as freqüências luminosas mais altas expressam alta carga de energia.

A tonalidade da representação dos copos de chope claro, indicando o principal produto da empresa, está em harmonia tonal com a cor vermelha. O contorno da forma e as áreas em amarelo escuro foram coloridos para mediar a relação de contraste com o vermelho e reforçar a coerência com o ambiente e o principal produto da empresa. $\mathrm{O}$ elemento circular reforça ainda mais a coerência, porque segue a tradição dos rótulos de cerveja e, também, das bolachas de chope, além de organizar a composição e tornar a forma mais pregnante.

Os três copos representados no centro da marca indicam que o ambiente é frequentado por grupos de pessoas, reforçando o aspecto coletivo. A ilustração sugere alegria com formas que crescem, se expandem e transbordam, indicando que o ambiente está ligado à descontração. $\mathrm{O}$ contraponto e determinado pela tipografia "Albertus", de alta legibilidade, que sugere seriedade e confiança, de modo coerente com o ambiente divertido, porém caseiro e familiar.

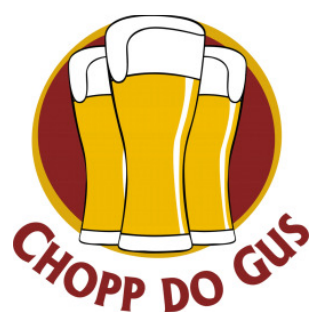

Figura 4: Proposta escolhida 
O símbolo icônico representa e evidencia o chope que, como foi dito, é o principal produto, cuja qualidade representa o grande diferencial da empresa. A perspectiva da figura, composta de baixo para cima, contribuiu para que a assinatura visual ficasse mais imponente, ressaltando o valor do conjunto, cores e figuras, e ampliando os sentidos da marca gráfica.

\section{CONSIDERAÇÕES FINAIS}

O presente trabalho permitiu ao grupo o desenvolvimento de um método de trabalho para utilização em projetos de Design Gráfico. O desenvolvimento da metodologia possibilitou uma visualização de todo o projeto.

No caso de empresas de pequeno porte, também, há a necessidade de uma maior preocupação com o branding, que considera o posicionamento e a gestão da marca, como fatores dependentes do tipo de público e de seus desejos e emoções que a marca pretende despertar. No estudo de caso do presente artigo, as relações e as identificações propostas entre a marca e o posicionamento da empresa foram atingidas. Isso se deu na medida em que a marca apresenta o produto, expressando os sentidos de coletividade, rusticidade, tradição, alegria e informalidade com simplicidade familiar e seriedade. Esses sentidos foram considerados coerentes com os desejos e sonhos do público visado pela empresa. Um símbolo bem produzido indica profissionalismo e estabelece o aumento do reconhecimento e da credibilidade da marca. Isso foi confirmado por meio de entrevistas informais realizadas junto aos públicos interno e externo.

\section{REFERÊNCIAS}

BAXTER, Mike. Projeto de produto: Guia prático para o desenvolvimento de novos produtos. São Paulo: Edgar Bucher Ltda, 1998.

BOMFIM, Gustavo Amarante. Metodologia para Desenvolvimento de Projetos. João Pessoa, Editora Universitária/ UFPB, 1995.

GOBÉ, Marc. A Emoção das Marcas: conectando marcas às pessoas. - Rio de Janeiro: Campus, 2002.

MARTINS, J.R. Branding. Um Manual para Você Criar, Gerenciar e Avaliar Marcas. 3 ed. Revista Ampliada. 2006.

MUNARI, Bruno. Das coisas nascem as coisas. Tradutor Jose Manuel de Vasconcelos. São Paulo: Martins Fontes, 1998.

NUNES, G. Gestão estratégica da marca. In: Revista F aebusiness, n.7, nov. 2003.

SANTOS, Flavio Anthero dos. O Design como diferencial competitivo. Itajaí, SC: Editora da Univali, 2000. 